leukaemia. Other specialist interests are covered by reviews of sexually transmitted disease and glomerulonephritis.

Inevitably, with the growing yield of reports on the results of coronary artery surgery, the chapter on surgery for coronary artery disease is somewhat dated in this respect. It is also perhaps churlish to criticize the chapter on the prostaglandins for missing out one's favourite fields, as of course it could not possibly cover them all. The editors have deliberately interpreted medicine widely - hence additional chapters on the treatment of phobic and obsessional states, slow viruses of the CNS, acclimatization to heat and cold, and infertility.

With so much of more immediate interest to general physicians than, say, obsessional states (which are rare in psychiatric practice), the editors might consider narrowing the range of topic in future editions.

This is a book for the browser and for those wanting reviews of the specific topics. As such it can be warmly recommended.

Recent Progress in Pediatric Endocrinology. Proceedings of the Sereno Symposia, vol. 12

Edited by G. Chiumello \& Z. Laron. Pp. 325, illustrated. London, New York, San Francisco: Academic Press, 1977. £10.00.

The reader who turns to this book for a general review of new developments in paediatric endocrinology will probably be disappointed. Recent Progress in Pediatric Endocrinology records the proceedings of a symposium held in Milan in October 1976. The main themes of the meeting were on carbohydrate metabolism, puberty disorders and hypertension, and guest lectures were combined with shorter communications. Some of the papers will be of general interest, particularly the review of the hormonal control of energy metabolism by Drash, papers on hyperinsulinism in infancy and the long-term effects of hypoglycaemia from Philadelphia and Baltimore, and wise words on delayed puberty by Prader. Dr Maria New's account of her search for an unidentified steroid which causes hypertension and a paper on the possible protective effect of breast feeding in congenital hypothyroidism will also be of interest. However, a fairly high proportion of the thirty-one contributions are short papers describing 'recent results', and this has resulted in the production of an uneven and rather unsatisfactory book.

\section{Studies in Acute Heart Failure}

By Ronald D. Bradley. Pp. 78, illustrated. London: Edward Arnold, 1977. Soft cover $£ 2.95$.

This book reports a collection of observations made in an intensive care unit, into the nature and treatment of heart failure. Much of the theory behind the book lies upon ventricular function curves. In addition to previous work, which has been published, unpublished anecdotes occur throughout the book. On some occasions these have not been critically analysed and correspondingly there is a danger that some dogma may be generated. The reader is taken through the theoretical and practical management and diagnosis of patients presenting in the intensive care unit with heart failure. Correspondingly, this book is essential reading for clinicians involved with the care of the acutely ill patient and also ideally, anaesthetists. This book carefully explains the theory underlying the principles used in practice and often illustrates these points with figures and chest $\mathrm{X}$-rays to exemplify the clinical conditions. The care of the patient after cardio-pulmonary bypass, or the patient with pulmonary embolism with raised pulmonary vascular resistance is dealt with, but only in scant fashion. Also the drug treatment of heart failure, particularly utilizing some of the newer inotropic agents, receives little attention. The reference section is also limited.

This book does not purport to be comprehensive. It should become essential reading to all clinicians involved in the care of the acutely ill patient. I feel sure it will be updated by a more comprehensive further addition.

\title{
Notices
}

\section{REGIONAL RED CROSS BLOOD BANK GRONINGEN - DRENTHE 3rd Annual Symposium on Blood Transfusion}

A two day meeting on OPEN HEART SURGERY AND BLOOD TRANSFUSION will be held in Groningen, The Netherlands, on October 26 and 27, 1978

Information and registration: Cees Th. Smit Sibinga, M.D., Ph.D., Regional Red Cross Blood Bank, Groningen-Drenthe, Oostersingel 59, Groningen, The Netherlands.

April 27-28, 1979

'OBSTETRIC ANALGESIA AND ANESTHESIA,' to be held at the Colonnade Hotel, Boston, Massachusetts. Sponsored by the Department of Anesthesia, Boston Hospital for Women and Harvard Medical School, Boston, Massachusetts.

This course is designed to present a review and update on obstetric anesthetic management.

Course directors: Gerard W. Ostheimer, M.D. and Milton H. Alper, M.D.

For more information, write: Department of Continuing Education, Harvard Medical School, 25 Shattuck Street, Boston, Massachusetts 02115. 